\title{
The "Good Professor" as Perceived by Experienced Teachers Who are Graduate Students
}

\author{
Mordechai Miron $^{1} \&$ Miriam Mevorach ${ }^{2}$ \\ ${ }^{1}$ School of Education, Tel Aviv University, Tel Aviv, Israel \\ ${ }^{2}$ Levinsky College of Education, Tel Aviv, Israel \\ Correspondence: Mordechai Miron, School of Education, Tel Aviv University, Tel Aviv, Israel
}

Received: May 8, 2014

doi:10.11114/jets.v2i3.411
Online Published: May 26, 2014

URL: http://dx.doi.org/10.11114/jets.v2i3.411

\begin{abstract}
The aim of this study was to uncover our graduate students' perceptions of who is a good professor. Although the data were collected and analyzed on an Israeli sample, the findings can contribute to the planning of graduate programs for experienced teachers and can extend the theoretical understanding of how to promote learning among experienced adult learners in general. The qualitative phenomenological study examined ninety experienced teachers, who were students at a graduate college of education. They were asked to indicate three characteristics and describe classroom events that reflect a "good professor." In addition, we analyzed the feedback questionnaires that were administered at the end of each semester. The data presented students' perceptions of the "good professor." The findings revealed three domains of characteristics: first, the relationship between professor and students; second, methods of instruction; and third, the professors' knowledge. The same domains were found in the students' descriptions of the teaching events and in their feedback at the end of the semester. Their expectations and needs are different from those of undergraduate students.
\end{abstract}

Keywords: good professor; graduate program; experienced teachers

\section{Introduction}

"On the first day of the first course, I met a brilliant lecturer. The combination between her personality and her profound knowledge were the stimulus for me to start on a voyage of fascinating inquiry that lasted two years, and I hope it will never stop" (A graduate student in the program).

The aim of this study was to uncover graduate students' perceptions of what good teaching is or, in other words, who is a good professor. Although the data were collected and analyzed in the Israeli context, the findings may contribute to planning graduate programs for experienced teachers and extend our theoretical understanding of how to promote learning among experienced adult learners in general.

\section{Theoretical Background}

Since all the participants were experienced teachers, it was assumed that their view of what makes a good professor derives from two sources: their teaching experiences and their learning experiences (Mevorach \& Miron, 2011a). In this earlier research, a huge change was seen in graduate students. It was found that their new abilities to analyze their own work through academic lenses and their expanded desire for higher degrees was part of their ongoing personal development. It seems important to uncover the contribution of the components that helped to create this change: the program (Mevorach \& Miron, 2011b), the students' role perceptions (Mevorach \& Miron, 2011a) and the lecturer's. characteristics, the latter being the focus of this paper. If indeed the lecturer's characteristics are significant in affecting the change, then students' views might illuminate a profound and enigmatic question: what makes a successful college professor? Several researchers have tried to find common understandings or definitions of a good university teacher (Miron, 1983), an expert university teacher (Berliner, 2001), an excellent lecturer (Goldstein \& Benassi, 2006), a tertiary teacher (Kane et al. 2004), a good university lecturer (Leibowitz, van Schalkwyk, Ruiters, Farmer \& Adendorff, 2011), and having a calling to a mission (Helm, 2006). All used different terms for a similar concept that expresses the quality of a person whose aim is to present new knowledge to students. In this paper, the terms good teacher, good university lecturer, and good professor were used synonymously. And the term "good professor" was used, so as to distinguish the concept of college or university teaching from teaching on other levels. 
One of the questions that stir interest among those who deal with higher education is what makes good and effective instruction. Most teacher educators would agree that one of the primary goals of a teacher preparation program is to teach individuals how to become good teachers. What is open to debate is exactly what the characteristics of good teachers are (Murphy, Delli, \& Edwards, 2004). Good teaching is not easy to identify and measure. It most likely falls into the elusive category of "I can't define it, but I know it when I see it" (Jones, 2008, p. 95).

Lowman (1996) defined the effective teacher as a presenter of material in a clear and engaging manner; he focused on interpersonal relationships and establishing rapport with students. His detailed analysis included 39 descriptors grouped into four dimensions: intellectual excitement, interpersonal concern, effective motivation and commitment to teaching. The most common adjective used to describe an exemplary teacher was enthusiastic; other important descriptors were knowledgeable, inspiring, concerned, helpful, dedicated, humorous, and caring. Goldstein and Benassi (2006) performed principal component analysis to measure the good professor and revealed two dimensions - process and structure. Process includes factors such as focusing on students' knowing the definitions of concepts; closely following an outline when teaching in class; and exposing the class to ideas that promote self-examination on the part of the students. Structure relates to establishing a warm relationship with students; accepting students' feelings; and building relationships of mutual trust among students. These factors are consistent with Lowman's findings. Wood and Harding (2007) defined ten dimensions of excellence in teaching. Most are consistent with those found by Goldstein and Benassi (2006), to which they add innovation and scholarship. Similarly, Leibowitz et al. (2011) examined a group of academics who had been designated as 'good lecturers' by top performing students. They found that the lecturers noted four main aspects to explain their becoming good lecturers: biography, contextual influences, disposition (emotion and attitudes), and steps taken to enhance teaching. Leibowitz and her colleagues argued that the process of becoming a good university lecturer requires interplay between those components.

Berliner (2001) argued that it is difficult to define an expert teacher. Most of the definitions relate to the 'successful' teacher and ignore the qualities of the 'good' teacher. Berliner noted that to be able to define an expert teacher, one needs to refer to talent, context and pedagogy. Indeed, when reviewing the theory and data regarding this topic, we found that it is almost impossible to separate the concept of teaching from the concept of learning. For example, Bruner (1996) presented models of teaching intertwined with compatible models of learning.

It is difficult to separate the concept of teaching as a process and the characteristics of a teacher as a subject. In characterizing teaching, Sockett (2008) identified four typical models that relate to teaching, to the character of the teacher, and to the perception of what makes a good professor: a) the scholar-professional model, b) the nurture-professional model, c) the reflective and adaptive model, and d) the moral agent professional model. The first model, the scholar-professional, is based on the understanding that the cardinal goals of teaching are acquiring knowledge and cultivating the intellect. The second model, the nurture-professional model, focuses on relations between the professor and the student, with the teacher in a nurturing role. In the reflective-adaptive model, the professor can adapt to any teaching situation and can adjust teaching strategies to students' learning. In the fourth model, the moral-agent, professors are people who believe in truth and being truthful, first and foremost to themselves and afterwards to their students.

In addition, both the professor's method of instruction and personal characteristics are embedded in the context of the academic institution and the specific program.

\subsection{The Nature of the Program}

The master's degree (M.Ed.) program at the college of education whose students participated in this study reflects the importance of combining up-to-date academic knowledge with experience in the educational field. This new program addresses the two major aspects of the teacher's work: the education and developmental advancement of the children, and optimal curriculum and instructional planning for various age groups. The program affords experienced educators, working in a wide variety of contexts, the opportunity to focus on the analysis of "education in action" (Genishi, Ryan, Ochsner, \& Yarnall, 2001). Emphasis is on the improvement of professional practice through systematic inquiry and projects undertaken in the workplace. The participants are expected to develop increasing respect for evidence through which to examine their professional roles. In addition, they are expected to initiate and sustain change, both individually in their own practice and generally within the educational system. The current study refers to similarities and differences between perceptions of the students relating to the question: Who is a good professor at a College of Education?

The 2-year graduate program is constructed as an additional layer above the B.Ed. in education. Unlike B.Ed. studies, which focus on general foundations of developmental and disciplinary knowledge with a pedagogical emphasis, this program affords another layer of additional developmental, managerial and advanced curricular knowledge in combination with the students' personal experience. The program includes several components. The general education component includes courses that provide students with a broad grounding in current issues in education and the 
opportunity to hold high-level academic discussions on topics relevant to their daily work. In the research methods component, students are required to conduct research that is conducive to their work. It is anticipated that students will explain, justify, and defend their approaches. This facilitates further expansion of the students' awareness of the importance of the cultural aspects that construct children's identity in the society in which they live.

The core of the M.Ed. program is an applied research project. The students' courses assist them in planning and executing the project. The students identify and examine major issues and dilemmas in their work. Their research report includes a theoretical discussion of the topic, data collected by various methods, data analysis, and theoretical and professional conclusions drawn from the data (Moss \& Dahlberg, 2008).

This research focused on how first- and second-year graduate students as well as those who were just embarking on graduate studies perceive the good professor. All were professional teachers who had come back to academia after years of teaching. This context enabled to expand the understanding of students' professional progress and to plan, construct and implement an optimal learning environment for them.

\section{Method}

\subsection{Research Design}

The current qualitative study was based on a phenomenological approach meant to explore the nature of good teaching and who is the good professor as perceived by the students in the programs. The phenomenological research tradition deals with conscience and the whole direct personal experience. Husserl $(1931,2012)$ argued that natural knowledge is always combined with experience and one cannot differentiate the essence from the fact. That tradition enables to the researches to listen to the participants' own thoughts, perceptions, and insights. Using content analysis, we investigated how the good professor and good teaching were perceived by graduate students who were experienced teachers.

\subsection{Participants}

Ninety students at a graduate college of education, aged 27-56, participated in the study. All held a first degree in early childhood and elementary education and a teaching certificate. They received their undergraduate training at a variety of academic institutions: universities, colleges of education, and general colleges. Their teaching experience ranged from 3 to 24 years: 42 students had 3-10 years of experience, 20 had 11-20 years of experience and 28 had 21-24 years of experience. They came from all over the country of Israel: small towns, cities, Arab villages, kibbutzim, and agricultural villages. All the participants agreed to have their data used for the research. There were three groups among the participants: 1) those who had just been accepted into the program (hereafter referred to as "candidates"); 2) first-year students and 3) second-year students. Each group included 30 students.

\subsection{Procedure}

The participants responded anonymously and voluntarily to open questions. The purpose of the study was clearly explained to them, and they approved the use of data for research matters. The written questions were presented by the external researches who at that time didn't work at the college and the participants never met him. The other researcher was retired at the time that the data collection was performed. They wrote their responses on an anonymous paper, were collected by the participants, and were submitted to the researcher. The students were asked to identify the three most important characteristics of a "good" college professor? In addition, they were asked to describe a classroom event that reflects the good professor without referring to a particular one. The first group responded during an orientation meeting before beginning their studies. First- and second-year students responded during class meetings (with the absence of the lecturer of the class) toward the end of the year. The responses were grouped into thematic clusters. We also analyzed first- and second-year students' anonymous, periodical written feedback which was collected by the research unit, regarding their courses. The feedback is usually collected at the end of every semester and submitted to the head of the program. The feedback questionnaire included Likert-type and open-ended questions. For this paper, we analyzed only the open-ended questions.

Each researcher organized the written responses from all sources of the data into clusters independently by content analysis method. The clusters were then compared until agreement was reached on the final domains. Analyzing the data from different sources by two independent researchers increased the creditability of the study.

\section{Results}

First, we describe the characteristics of a good college professor as perceived by the students. Then we present findings from the written descriptions of events relating to a "good professor" in class. Finally, we present findings from the students' written feedback.

The domains of the good professor - personal relationship, method of instruction and knowledge in the field - as perceived by the students can be seen in Table 1. The students attached primary importance to the relationship established between the professor and the students: a good listener, sensitive to students' needs, respectful of students' 
opinions and rights, and a person who relates to students as equal human beings. Of secondary importance were methods of instruction, such as delivery of the subject matter, advancement of critical and scientific thinking, ability to organize the lesson, creating a dialog with the students and among the students themselves. The professors' knowledge in their field of instruction was next in importance, as experts in the field and involved in research.

Table 1. Domains of the good professor among the three groups: candidates, ${ }^{*}$ first- and second-year graduate students (frequency of utterances)

\begin{tabular}{lllll}
\hline Domains & $\begin{array}{l}\text { Personal } \\
\text { relationship }\end{array}$ & $\begin{array}{l}\text { Methods of } \\
\text { instruction }\end{array}$ & $\begin{array}{l}\text { Knowledge in the } \\
\text { field }\end{array}$ & Total \\
\hline Candidates & 22 & 17 & 19 & 58 \\
First-year & 14 & 18 & 3 & 35 \\
Second-year & 22 & 8 & 15 & 45 \\
Total & 58 & 43 & 37 & 138 \\
\hline
\end{tabular}

* This group had been accepted but had not yet begun studying.

Table 1 shows that there were only small differences between the candidates' perceptions of the three domains. Since they had not yet started their studies, their perceptions were probably based mostly upon their expectations, rather than on actual experience with advanced studies. First-year students placed methods of instruction first; very few of their responses related to the professors' knowledge in the field. Second-year students placed the personal relationship first and methods of instruction last.

Next, we present findings from students' descriptions of events that reflect a good professor. In the domain of personal relationships, the candidates described situations in which "the lecturer is willing to help and listen during the final written report in the seminar" or "she relates to students' personal needs" and "considers the fact that the students have a heavy and intensive load of studies," or understands the students' point of view: "She relates to the diversity among the students." The second domain was the professor's knowledge, including utterances such as "the professor is knowledgeable and well informed in his area of teaching"; he is also "an expert in research methodology" and "a person having high professional eminence." Regarding the professors' methods of instruction, they noted that "the student asks questions and the professor had the time and patience to explain"; he gives "examples and demonstrates the material in an exciting manner." In addition, "he relates previous knowledge to new knowledge and opens new channels of thinking."

The candidates related first and foremost to the personal relationship with the professors. Their expectations were that "the professor will be reachable and available when he is needed and all that in a pleasant manner"; they also pointed out the need for a "human personal relationship" and that "he pays attention to students' wishes." In second place, their expectations were in the domain of methods of instruction. There were remarks such as "the professor who attracts students' attention through a story, a demonstration, or a movie while describing the event in an unconventional way.". The professor is expected "to relate the experience to theoretical knowledge and back to experience." Lastly, they expected the professor to be knowledgeable and well-rounded, making comments such as "the professor should have understanding and be an expert in his subject matter and other related areas."

First-year students related mostly to methods of instruction, noting events such as "the professor sends summaries of lessons through the mail," trying to make sure that everybody can cope with the subject matter: "she doesn't hurry to cover the content, and makes sure that everybody understands," or supervising academic writing: "she knows how to guide and explain how to refer to references." Other events related to personal relationships: "the professor is attentive to all the students and responds to their needs" and has the ability to identify and distinguish the individual within the group: "the professor recognized me and knew who I was from the first class meeting." The fewest events related to the professor's knowledge: "I was impressed with the knowledge she showed when discussing research and its results."

In the second year, the order was slightly different: first was the personal relationship: "the professor relates with respect to students' remarks, speaks with students on the same level and respects students'opinions even when they are not compatible with his own" or she is a professional who "accepts me both as an individual and as an equal." Next came methods of instruction: “one who listens, and sometimes changes the topic of the lesson to suit students' interests. Brings interesting and colorful materials, and answers students' questions." In third place was the professor's knowledge: "rich, full of knowledge and stimulates thinking" or "his/her profound knowledge in the field."

It is interesting to note that candidates' choices were similar to those of second-year students. Both groups characterized the good professor first as one who relates to students personally. But their choices may stem from different sources. While the candidates described events that reflected their previous experiences and expectations, second-year students reflected on their actual experiences with professors.

Next, we present findings from the students' written feedback. The students were regularly asked to answer a feedback 
questionnaire that included an open-ended question. We decided to analyze the open-ended question in order to find out if these or other dimensions appeared in the students' feedback. Since the questionnaire was anonymous and administered at the end of the year, the candidates were not included. In addition, since the classes included both firstand second-year students, we could not distinguish between the groups and therefore the data from the two groups were analyzed together. In the students' responses, we found the same three domains that we found in the characteristics of the good college professor and in the descriptions of the events.

Regarding personal relationships, students' comments included: "the professor shows passion and sensitivity to students' needs" and "she is a receptive and a kind person." Next, in the domain of methods of instruction, we found "the professor uses varied teaching methods such as demonstrations, illustrations and examples from real life situations." The third domain was the professor's knowledge: "the professor possesses profound knowledge, knows the subject matter well and is an expert in his field."

\section{Discussion}

The aim of this study was to investigate graduate students' perceptions of the good college professor. The context of this study is the academic college of education, which is a unique environment. It combines high sensitivity to the dyad relations of teaching-learning and educational research (Bruner, 1996; Berliner, 2001; Mevorach \& Strauss, 2012). This combination stems from the tendency to incorporate research into the process of educating teachers and preparing them for their multi-domain tasks in the community (Darling-Hammond, 2010). Following the process of change that occurs in the profession of college professor, the need arose to reexamine students' conceptions of what a good professor is.

After analyzing data from various sources, we found three of the four models that Sockett (2008) identified. The most frequent model was the nurture-professional model, which in our data was identified as the 'personal relationship' domain. That model was found mostly among candidates and second-year students. Next was the reflective-adaptive model that was presented as the 'methods of instruction' domain, which was found mostly among first-year students. The third model was the scholar-professional that was expressed as the 'knowledge of the fields' domain, and found mainly among candidates and second-year students. Sockett's fourth model, the moral agent, did not appear in our data. The reason may stem from the fact that our research instrument was not sensitive enough to the moral component.

It is interesting to note the differences between first- and second-year students relating to the scholar-professional model and the similarity between candidates and second-year students, although their choices may stem from different sources. While the candidates perceived the source of knowledge as external and presented by the professor, second-year students are much more knowledge-professional oriented and perceive themselves as partners in creating knowledge. This finding is compatible with Hofer and Pintrich (1997), who found that the perception of the source of knowledge is developmental: from an external source toward an internal source, based on accumulated years of study. In addition, they found that the more advanced the students are in academic studies, the more they tend to stress the source and importance of knowledge.

Another point of interest is the very small differences among the three domains in the choices of the candidates. It seems that not having experienced advanced studies for a significant period of time prevented them from crystallizing a distinctive domain. In order to develop an expert teacher, in addition to abilities and context, one needs the aspect of practice, as Berliner (2001) pointed out.

The reflective-adaptive model was more popular among first-year students. This may be due to the fact that most of them came to the college after having been away from academic studies for many years. Their initial need is to find ways of becoming reacclimatized to methods of instruction in an academic institution.

As to the nurture-professional model, second-year students emphasized the interpersonal relationships between the professor and the students. It seems that first-year students taking general courses are more interested in methods of transmitting knowledge, while second-year students, who are required to submit their seminar papers and research projects, seek a one-on-one tutoring relationship.

In analyzing Sockett's nurture professional model, an additional layer emerged. The professor does not only relate to the students as adult learners with teaching experience who have come to study, but also, in a democratic manner, relates to them as equals. The professor is attentive, encouraging, counseling, and in addition, he listens and accepts students' opinions. It seems that the professor is no longer the only source of knowledge, as Bruner argued (1996); the students learn from one another and sometimes the professor learns from his students. This finding may be interpreted as a fifth model that can be added to Sockett's four models. This "professional-democratic" model may serve as a theoretical contribution to the field: a new academic state of mind of a successful college and university professor.

These findings should be considered by those who are developing advanced academic studies for students with teaching experience. Their expectations and needs are different from those of undergraduate students and from the typical graduate students. These students expect to be exposed to a variety of teaching methods suitable for the mature learner 
(Knowles, Holton \& Swanson, 2011); they expect personal relationships between the professor and the students, and they seek professors on the highest level. Further research might expand the knowledge by extending the domains of research into areas such as andragogy and moreover, teachers as adult learners. Although the data were collected and analyzed on a specific population it can illuminate the practical and theoretical aspects of higher education teaching. Since the participants themselves were experience teachers, their perception stems from intuition, praxis and theory that combine the complicated world of teaching and learning,

\section{References}

Antonakis, J., Cianciolo, A. T., \& Sternberg, R. J. (Eds.). (2004). The nature of leadership. Thousand Oaks, CA: Sage.

Berliner, D. C. (2001). Learning about and learning from expert teachers. International Journal of Educational Research, 35, 463-482. http://dx.doi.org/10.1016/S0883-0355(02)00004-6

Bruner, J. (1996). The culture of education. Cambridge, MA: Harvard University Press.

Darling-Hammond, L. (2010). Teacher education and the American future. Journal of Teacher Education, 61, 35-47. http://dx.doi.org/10.1177/0022487109348024

Goldstein, G. S., \& Benassi, V. A. (2006). Students' and instructors' beliefs about excellent lecturers and discussion leaders. Research in Higher Education, 47(6), 685-707. http://dx.doi.org/10.1007/s11162-006-9011-x

Helm, M. C. (2006). Teacher disposition as predictors of good teaching. The Clearing House, 79(3), 117-118. http://dx.doi.org/10.3200/TCHS.79.3.117-118

Hofer, B. K., \& Pintrich, P. R. (1997). The development of epistemological theories: Beliefs about knowledge and knowing and their relation to learning. Review of Educational Research, 67(1), 88-140. http://dx.doi.org/10.3102/00346543067001088

Jones, A. (2008). Preparing new faculty members for their teaching role. New Directions for Higher Education, 143, 93-100. http://dx.doi.org/10.1002/he.317

Kane, R., Sandretto, S., \& Heath, C. (2004). An investigation into excellent tertiary teaching: Emphasizing reflective practice. Higher Education, 47(3), 283-310. http://dx.doi.org/10.1023/B:HIGH.0000016442.55338.24

Knowles, M. S., Holton, E. S. \& Swanson, R. A. (2011). The adult learner. ( $7^{\text {th }}$ edition). Oxford, U.K.: Elsevier Inc.

Lowman, J. (1996). Characteristics of exemplary teachers. New Directions in Teaching and Learning, 65, 33-40. http://dx.doi.org/10.1002/t1.37219966508

Leibowitz, B., van Schalkwyk, S., Ruiters, J., Farmer, J., \& Adendorff, A. (2011). "It's been a wonderful life": Accounts of the interplay between structure and agency by "good" university teachers. Higher Education, 63(3), 353-365. http://dx.doi.org/10.1007/s10734-011-9445-8

Mevorach, M., \& Miron, M. (2011a). Experienced early childhood teachers as graduate students: A process of change. Early Childhood Education Journal, 39(1), 7-16. http://dx.doi.org/10.1007/s10643-010-0442-9

Mevorach, M., \& Miron, M. (2011b). Master's program in Israeli Colleges of education: Anew learning opportunity in early childhood education. Journal of Early Childhood Teacher Education, 32, 287-296.

Mevorach, M. \& Strauss, S. (2012). Teacher educators' in-action mental models in different teaching situation. Teacher and Teaching: Theory and practice, 18 (1), 25-41. http://dx.doi.org/10.1080/13540602.2011.622551

Miron, M. (1983). What makes a good teacher? Higher Education in Europe, 8(2), 45-53. http://dx.doi.org/10.1080/0379772830080206

Murphy, K. L., Delli, A. M., \& Edwards, M. N. (2004). The good teacher and good teaching: Comparing beliefs of second-grade students, preservice teachers and inservice teachers. The Journal of Experimental Education, 79(2), 69-92. http://dx.doi.org/10.3200/JEXE.72.2.69-92

Sergiovanni, T. J. (1995). The principalship: A reflective practice perspective. Boston, MA: Allyn and Bacon.

Sockett, H. (2008). The moral and epistemic purposes of teacher education. In M. Cochran-Smith, S. Feiman-Nemser, D. J. McIntyre \& K. E. Demers (Eds.), Handbook of research on teacher education. Enduring questions in changing contexts (3rd ed., pp. 45-65). New York and London: Routledge.

Wood, L. N., \& Harding, A. (2007). Can you show you are a good lecturer? International Journal of Mathematical Education in Science and Technology, 38(7), 939-947. http://dx.doi.org/10.1080/00207390701582112

\section{(cc) $\mathrm{EY}$}

This work is licensed under a Creative Commons Attribution 3.0 License. 